\title{
ENVELHECIMENTO POPULACIONAL NO VALE DO RIO PARDO: ESTUDO SOBRE EDUCAÇÃO E GÊNERO
}

\author{
Deise Gabriela Frantz ${ }^{1}$ \\ Alice Raquel Piovesan ${ }^{2}$ \\ Silvia Virginia Coutinho Areosa ${ }^{3}$
}

\section{RESUMO}

Este artigo versa sobre a educação e o gênero dos idosos residentes no Vale do Rio Pardo/RS, apresentando resultados obtidos a partir da sistematização de dados secundários do Instituto Brasileiro de Geografia e Estatística (IBGE), dos censos demográficos dos anos 2000 e 2010. Neste estudo analisa-se o acesso dos idosos à educação em relação ao gênero. Percebeu-se uma diferença significativa com o passar dos anos, de modo que no censo de 2010 as mulheres se encontram em maior número em todos os níveis escolares, diferente do censo de 2000, onde a população feminina era marcada pelo pouco acesso à escolarização, uma vez que sua função social era pré-determinada como mãe, esposa e dona de casa. Este fenômeno atrelado ao modelo patriarcal vem mudando nas ultimas décadas, com a igualdade de gênero, e pode ser observado nos índices escolares do censo 2010.

Palavras-chave: Educação. Gênero. Idosos.

\begin{abstract}
This article focuses on education and gender of the elderly residents in the Vale do Rio Pardo/RS, presenting results obtained from the systematization of secondary data from the Brazilian Institute of Geography and Statistics (IBGE), of the demographic censuses of 2000 and 2010. This study examines the access to education of the elderly regarding gender. Noticed a significant difference over the years, so that in the 2010 census women are in greater numbers at all educational levels, different from the 2000 census, where the female population was marked by poor access to schooling, once its social function was predetermined as a mother, wife and homemaker. This phenomenon linked to the patriarchal model has been changing in recent decades, with the gender equality, and can be observed in the school census indexes 2010.
\end{abstract}

Keywords: Education. Gender. Seniors.

\section{INTRODUÇÃO}

Os países considerados do Terceiro Mundo vêm apresentando, nas últimas décadas, um progressivo declínio na taxa de mortalidade e, mais recentemente, nas taxas de natalidade. A associação destes dois fatores faz com que haja um aumento demográfico no que diz

\footnotetext{
${ }^{1}$ Acadêmica do Curso de Psicologia da Universidade de Santa Cruz do Sul - UNISC. <deisegf@mx2.unisc.br>

${ }^{2}$ Acadêmica do Curso de Serviço Social da Universidade de Santa Cruz do Sul - UNISC. <alicepiovesan@yahoo.com.br>

${ }^{3}$ Professora do Programa de Pós Graduação em Desenvolvimento Regional e do Curso de Psicologia da Universidade de Santa Cruz do Sul - UNISC. <sareosa@unisc.br>
} 
respeito a população idosa. $\mathrm{O}$ envelhecimento populacional, então, não se refere nem a indivíduos, nem a cada geração, mas, sim, à mudança na estrutura etária da população, situação que transforma também o modo de ver as pessoas idosas na sociedade (CARVALHO; GARCIA, 2003).

Esta mudança na estrutura etária é percebida com maior intensidade no sexo feminino. Diante disso, estudos apontam que uma das características do envelhecimento populacional é a feminilização da velhice, assim, o fator gênero se constitui como um elemento fundamental para se pensar o processo de envelhecimento (LIMA; BUENO, 2009).

No Brasil, como em outras partes do mundo, o acesso à educação está associado à questão do gênero, ou seja, remete às representações sociais construídas historicamente em torno das características sexuais. No campo da educação, as mulheres apresentaram níveis educacionais inferiores aos dos homens durante muitos anos. Este fato está atrelado à história da humanidade, já que por muito tempo se vivenciou um modelo cultural patriarcal em que a mulher encontrava-se subjugada ao homem. Na sociedade atual, esta realidade está mudando, na medida em que há uma ruptura com o modelo patriarcal, sendo a igualdade de gênero uma busca constante para a redução das diferenças sociais entre mulheres e homens. A igualdade de gênero é uma prioridade política que perpassa o setor da educação, na medida em que promover a educação para todos é promover o desenvolvimento econômico e social de uma região e/ou país. (CARVALHO; GARCIA, 2003).

O envelhecimento da população é um tema que está se destacando e gerando diversos debates nos mais diferentes campos. Percebe-se mudanças significativas no que se refere aos hábitos, crenças, estilos e expectativa de vida, e a maneira que as pessoas estão sendo consideradas pela sociedade neste momento. Destaca-se, ainda, que o Brasil está envelhecendo de forma bastante acelerada. Tempos atrás, o envelhecimento não era um assunto que preocupava a sociedade, pois o tempo médio de vida era menor. Contudo, atualmente, o envelhecer tomou outro rumo e vive acompanhado por mudanças bastante importantes, tanto para o indivíduo quanto para a sociedade (AREOSA; AREOSA, 2008; SILVA, 2008).

Envelhecer é um processo biopsicossocial extremamente complexo, tanto para quem vive, como para a sociedade em geral. Mesmo sabendo que nesta época da vida o corpo fica mais frágil e remete a maiores cuidados, não pode-se esquecer que o idoso, apesar das dificuldades, continua participando da sociedade. Isto se dá, pois, muitas vezes, a idade é definidora das pessoas, fazendo-as submeter-se a normas sociais que não são benéficas a elas, negativando sua individualidade (MARQUES; PACHANE, 2010). 
O processo de envelhecimento acarreta uma série de mudanças, tanto morfológicas como funcionais. Tais mudanças diminuem a capacidade individual de enfrentar a demanda necessária para a manutenção de uma vida saudável, particularmente em situações nas quais há uma diminuição na reserva funcional, como, por exemplo, em condições de doença, de crise ou de perdas (PERRACINI; FLÓ; GUERRA, 2011). O envelhecimento perpassa a trajetória de vida pessoal e social do indivíduo e, considerando dessa forma, deve-se adotar precocemente um estilo de vida que favoreça um envelhecer saudável. Uma velhice saudável não depende unicamente da ausência de enfermidades, mas também a ausência de fatores de risco que contribuem para o desenvolvimento de uma morbidade. Busca-se insistentemente que as pessoas desenvolvam e exercitem hábitos de vida saudável na perspectiva de melhoria da qualidade de vida, inseridas em programas de promoção da saúde e prevenção das enfermidades, que estão centrados na realização regular de exercícios físicos, em uma alimentação equilibrada e na adoção de medidas profiláticas, como a imunização das pessoas acima de 60 anos de idade (DALLEPIANE, 2009).

Para além dos hábitos de vida saudável, é preciso viver/envelhecer melhor, e a maneira do idoso viver melhor é se sentir integrado socialmente. Dessa forma, as pessoas idosas procuram cada vez mais se inserir em novos contextos sociais, participando de diversos grupos de convivência, como associações, clubes, entre outros (MARTINS, 2004).

Relacionado à melhoria dos hábitos, percebe-se que, nos dias atuais, a educação está cada vez mais assumindo o papel de transformadora da sociedade, visto que é através dela que há a reformulação dos ideais sociais, político-científicos e culturais. É possível reconhecer a capacidade de mudança da população para distinguir entre o que julga correto ou errado. Portanto, é importante que a população, independente de idade, raça, gênero ou condição social, tenha educação completa e global, de modo a permitir o desenvolvimento de cada sujeito, para que realmente haja uma transformação e evolução social, que supere preconceitos, estigmas e estereótipos. Assim como ocorre com as demais fases de vida da população, a educação ocupa lugar de extrema importância na formação crítica do idoso, para que ele tenha condições de se manter mais ativo e mais consciente da própria velhice. Ocorre, na análise da velhice, a elucidação de faces da discriminação e opressão, devido ao fato de idosos serem considerados sujeitos improdutivos e que não possuem capacidade de aprender, ficando, então, caracterizado como um peso para a sociedade, com conhecimentos ultrapassados e experiências sem significado (SCORTEGAGNA; OLIVEIRA, 2010). No entanto, os idosos, através da educação, passam a ter uma maior inserção social, de modo que possam ser os protagonistas da sua vida, exigindo mais respeito, dignidade e os seus direitos. 
A educação não é a mesma em todos os tempos e lugares, e só pode ser entendida como uma prática social, que envolve uma multiplicidade de aspectos, que permeiam a vida total do homem (OLIVEIRA, 2012).

Neste contexto, o presente estudo apresenta dados referentes ao nível educacional dos idosos residentes na área de abrangência do Conselho Regional de Desenvolvimento (COREDE) do Vale do Rio Pardo - RS, a fim de analisar as diferenças entre gêneros neste território. Com isso, pretende-se problematizar o acesso à educação dos idosos a partir da questão do gênero.

\section{GÊNERO E EDUCAÇÃO: CONHECENDO A REALIDADE DOS IDOSOS RESIDENTES NO VALE DO RIO PARDO/RS}

O COREDE do Vale do Rio Pardo está localizado na região centro-oriental do estado do Rio Grande do Sul (RS), sendo composto por 23 municípios: Arroio do Tigre, Boqueirão do Leão, Candelária, Encruzilhada do Sul, Estrela Velha, General Câmara, Herveiras, Ibarama, Lagoa Bonita do Sul, Mato Leitão, Pantano Grande, Passa Sete, Passo do Sobrado, Rio Pardo, Santa Cruz do Sul, Segredo, Sinimbu, Sobradinho, Tunas, Vale do Sol, Vale Verde, Venâncio Aires e Vera Cruz. As informações apresentadas advêm da sistematização e análise de dados secundários obtidos através dos censos demográficos do Instituto Brasileiro de Geografia e Estatística (IBGE) referentes aos períodos de 2000 e 2010.

Para o inicio desta análise, faz-se importante abordar a população total, bem como a população de idosos do Vale do Rio Pardo. A população da região é composta por 418.141 habitantes, sendo que 60.120 possuem 60 anos ou mais, representando $14,37 \%$ da população total da região, o que demonstra a importância de estudos sobre essa população específica (IBGE, 2010). Quanto ao maior percentual de população idosa do Vale do Rio Pardo, destacam-se nos censos demográficos de 2000 e 2010, respectivamente, os municípios de Vale Verde (14,91\% e 18,54\%), Sinimbu (14,63\% e 17,18\%), General Câmara $(14,07 \%$ e $17,91 \%)$, Passo do Sobrado (13,79\% e 15,62\%), Candelária (13,29\% e 16,07\%), Encruzilhada do Sul $(13,28 \%$ e $15,98 \%)$ e Mato Leitão (12,7\% e 15,75\%), que tiveram um crescimento significativo nos percentuais de idosos. Devido ao fato do Vale do Rio Pardo compreender um grande número de municípios, os dados apresentados a seguir serão alusivos aos municípios que mais se destacaram quanto aos índices educacionais dos idosos. 
É importante salientar que os níveis educacionais dos anos de 2000 e de 2010 foram sistematizados pelo IBGE de formas diferentes. Os dados do ano de 2000 foram classificados em: Ensino Fundamental Incompleto $-1^{\mathrm{a}}$ a $3^{\mathrm{a}}$ série; Ensino Fundamental Incompleto $-4^{\mathrm{a}}$ a $7^{\mathrm{a}}$ série; Ensino Fundamental Completo; Ensino Médio Completo; Superior - Graduação; Superior (Mestrado). Já no ano de 2010, os dados foram classificados em: Sem Instrução ou Ensino Fundamental Incompleto; Ensino Fundamental Completo ou Ensino Médio Incompleto; Ensino Médio Completo ou Superior Incompleto; Ensino Superior Completo. Por esse motivo, os dados apresentados não podem ser comparados em sua totalidade, podendo haver divergências em alguns aspectos. O primeiro deles é que no ano de 2000 o Ensino Superior divide-se em graduação, bem como, em mestrado, nível este que não consta no censo demográfico de 2010. O outro aspecto é que, no ano de 2010, são apresentados dados relativos à população idosa sem instrução, nível que não foi identificado no censo demográfico de 2000 do IBGE, onde a categoria era Analfabetos.

Contudo, apesar das disparidades salientadas, ressalta-se que a análise dos dados dos dois últimos censos do IBGE originou subsídios significativos para a construção de conhecimento acerca do estudo sobre educação e gênero no Vale do Rio Pardo. A diferente metodologia utilizada pelo IBGE em 2000 e em 2010 realmente acarretou pequenas dificuldades na análise dos dados, porém, não impediu que se chegasse a uma conclusão.

Diante disso, ressalta-se que os dados analisados sobre o nível de escolaridade da população idosa dos municípios do Vale do Rio Pardo correspondem a uma amostra da população idosa do Vale do Rio Pardo, sendo necessária a realização de um estudo mais aprofundado que propicie a identificação de dados mais detalhados para poder conhecer a totalidade da situação escolar desta população.

Os dados, sistematizados conforme a classificação do IBGE, são apresentados nas Tabelas 1 e 2, referentes à escolaridade e ao gênero dos idosos residentes no Vale do Rio Pardo - RS.

Observa-se que no censo de 2000 as mulheres estão em maior número apenas nos níveis iniciais, de $1^{\mathrm{a}}$ a $7^{\mathrm{a}}$ série, e no Ensino Fundamental Completo, pois já no Ensino Médio Completo e Superior Graduação e Mestrado são os homens que estão em maior número. Mas esta diferença não é decorrente das características biológicas do ser humano, mas das condições históricas, culturais e estruturais de cada sociedade, ligadas ao modelo de sociedade patriarcal onde às mulheres cabia o espaço da casa, dos filhos e do marido. 
Tabela 1- Gênero e escolaridade dos idosos residentes no Vale do Rio Pardo - RS em 2000.

\begin{tabular}{lcccc}
\hline \multicolumn{1}{c}{ Escolaridade } & \multicolumn{2}{c}{ Homens } & \multicolumn{2}{c}{ Mulheres } \\
& Total & Porcentagem & Total & Porcentagem \\
\hline $1^{\mathrm{a}}$ a 3 ${ }^{\text {a }}$ Série Ensino Fundamental & 5.460 & $1,37 \%$ & 8.296 & $2,24 \%$ \\
$4^{\text {a }}$ a 7 Série Ensino Fundamental & 8.978 & $2,26 \%$ & 12.010 & $3,02 \%$ \\
Ensino Fundamental Completo & 718 & $0,18 \%$ & 904 & $0,22 \%$ \\
Ensino Médio Completo & 701 & $0,17 \%$ & 589 & $0,14 \%$ \\
Ensino Superior - Graduação & 436 & $0,10 \%$ & 393 & $0,09 \%$ \\
Ensino Superior - Mestrado & - & - & 10 & $0,001 \%$ \\
\hline
\end{tabular}

Fonte: IBGE, 2000.

Tabela 2 - Gênero e escolaridade dos idosos residentes no Vale do Rio Pardo - RS em 2010.

\begin{tabular}{lcccc}
\multicolumn{1}{c}{ Escolaridade } & \multicolumn{2}{c}{ Homens } & \multicolumn{2}{c}{ Mulheres } \\
& Total & Porcentagem & Total & Porcentagem \\
\hline $\begin{array}{l}\text { Sem Instrução ou } \\
\text { Ensino Fundamental Incompleto }\end{array}$ & 21.321 & $5,81 \%$ & 27.794 & $7,58 \%$ \\
$\begin{array}{l}\text { Ensino Fundamental Completo ou } \\
\text { Ensino Médio Incompleto }\end{array}$ & 2.062 & $0,55 \%$ & 2.635 & $0,71 \%$ \\
$\begin{array}{l}\text { Ensino Médio Completo ou } \\
\text { Ensino Superior Incompleto }\end{array}$ & 1.651 & $0,44 \%$ & 1.832 & $0,48 \%$ \\
Ensino Superior Completo & 1.137 & $0,30 \%$ & 1.440 & $0,39 \%$ \\
\hline
\end{tabular}

Fonte: IBGE, 2010.

Já os resultados obtidos pelo censo de 2010 demonstram que as mulheres estão em maior número em todos os níveis educacionais, percebendo-se uma mudança significativa na diferença de gênero e no acesso à educação. Por um grande período de tempo as taxas de alfabetização e os níveis educacionais dos homens eram superiores ao das mulheres. $\mathrm{O}$ costume social entre os séculos XIX e início do XX, ditava que a mulher deveria estar subordinada ao seu marido e ou ao seu pai e irmãos, os quais determinariam como deveria agir e o que deveria pensar. Em decorrência disto, as mulheres não tinham a possibilidade de estudar, já que o acesso à escolarização tornaria as mulheres mais autônomas e independentes, o que provocaria mudanças não desejáveis naquele momento histórico, na medida em que a mulher deveria se ocupar com a vida doméstica e familiar. Com o passar do tempo este papel foi se modificando e hoje as mulheres estão inseridas também no ambiente escolar e de trabalho (BELTRÃO; ALVES, 2009; DUARTE; LUSA; SILVA, 2011).

Segundo Melo (2005), o conceito de gênero trata de dar conta da vivência diferenciada das mulheres e dos homens, tanto na vida econômica como na social, das diversidades dos processos de socialização e dos padrões diferenciados que estes têm no seu comportamento. A desigualdade de gênero na expectativa de vida trouxe um resultado no qual 
existe uma proporção maior de mulheres do que de homens na velhice, e uma média de expectativa de vida para as mulheres de sete anos a mais do que para os homens (BIASOLIALVES, 2000; SALGADO, 2002).

No que diz respeito ao total da população idosa do Vale do Rio Pardo com nível de escolaridade na faixa de Ensino Fundamental Incompleto de $1^{a}$ a $3^{a}$ série no ano de 2000, percebe-se que há $13.756(3,61 \%)$ idosos nesta condição, sendo que há também 20.988 $(5,28 \%)$ que possuem estão na faixa de $4^{\mathrm{a}}$ a $7^{\mathrm{a}}$ série. Os municípios que apresentam maior índice de escolaridade entre $1^{\mathrm{a}}$ a $3^{\mathrm{a}}$ série do Ensino Fundamental são Rio Pardo (2.649 12,29\%), seguido de Candelária (1.544 - 8,89\%), Passo do Sobrado (284 - 8,41\%), Vale Verde (166 - 8,36\%), Herveiras (114 - 7,57\%) e General Câmara (372 - 7,26\%); e os municípios que apresentam maior índice de $4^{\mathrm{a}}$ a $7^{\mathrm{a}}$ série são Sinimbu $(871$ - 14,66\%), seguido de Mato Leitão (278 - 14,49\%), Vera Cruz (1.361 - 11,05\%), Passo do Sobrado (370 11,04\%), Vale do Sol (682 - 10,95\%), Venâncio Aires (3.629 - 10,11\%) e Santa Cruz do Sul (5.948 - 9,61\%). Destaca-se o município de Tunas, que não apresenta idosos com o Ensino Fundamental Incompleto de $1^{\mathrm{a}}$ a $3^{\mathrm{a}}$ série e 134 indivíduos residentes $(6,15 \%$ da população) que tem este nível educacional na cidade (IBGE, 2000).

Ainda, neste censo, o número de idosos analfabetos era de 39.169 (0,04\%) no Brasil, $723(0,02 \%)$ no Rio Grande do Sul é e 39 idosos no Vale do Rio Pardo, não contabilizando porcentagem significativa. Os municípios onde se identifica a existência de idosos analfabetos são Arroio do Tigre, com 4 idosos (0,05\%), Estrela Velha, com 5 (0,25\%), General Câmara, com 9 (0,18\%), Pântano Grande, com 5 (0,09\%) e Santa Cruz do Sul, com 16 (0,03\%) (IBGE, 2000).

Segundo dados do Instituto Nacional de Pesquisas Educacionais (INEP), publicados em 2003, a taxa de analfabetismo entre pessoas com 60 anos ou mais em 1996 era 37,4\%, em 1998, 35,9\%, e em 2001 era 34,0\%. Os dados mostram que o maior contingente de analfabetos encontra-se nos grupos etários mais idosos. Por isso, são eles que mais necessitariam de ações do governo na esfera da educação, que, hoje em dia, é a mais prejudicada pelo que podemos chamar de "exclusão educacional". É importante que haja diminuição de analfabetos idosos, para que estes possam conquistar autonomia, exercer sua cidadania, procurar soluções para seus problemas e saber resolvê-los (OLIVEIRA, 2012).

O idoso está, hoje em dia, com dificuldades de se adaptar ao mundo moderno e parte disso se deve ao fato de que esta geração teve deficiência educacional, pois vivia na época em que frequentar escola era privilégio de poucas pessoas. Por isso, a situação de analfabetismo pode ser considerada um fator limitante para a sobrevivência e qualidade de vida das pessoas. 
As diferenças no nível de analfabetização em questão de gênero refletem a organização social que se tinha anos atrás, que bloqueava o uso de escolas por mulheres, assim como aos mais pobres (SANTOS, 2010).

Nos dados referentes ao Brasil, percebe-se diferença entre os gêneros no que se refere ao Ensino Fundamental Incompleto de $1^{a} a 3^{a}$ série, identificando-se 1.612 .420 (1,88\%) homens idosos e 1.842.665 (2,16\%) mulheres idosas. Esta diferença se observa também no Rio Grande do Sul, que apresenta 120.685 (2,12\%) homens idosos e 153.255 (2,69\%) mulheres idosas. No Vale do Rio Pardo há 5.460 (1,37\%) homens idosos para 8.296 (2,24\%) mulheres idosas (IBGE, 2000).

Esta mesma diferença se observa quanto ao índice de escolaridade entre $4^{a}$ e $7^{a}$ série, sendo que no Vale do Rio Pardo havia 12.010 (3,02\%) mulheres idosas e 8.978 (2,26\%) homens idosos. No Rio Grande do Sul, o número de mulheres idosas com este nível educacional incompleto era de $231.533(4,05 \%)$ e de homens idosos era $172.235(3,01 \%)$. No Brasil, 2.034.015 (2,38\%) são mulheres e 1.659.801 (1,94\%) são homens (IBGE, 2000).

Dessa forma, este fenômeno ocorrido décadas atrás desencadeia, ainda nos dias de hoje, consequências especialmente em relação ao nível educacional dos idosos do sexo feminino, nível este que se manteve bastante inferior devido aos fatores vivenciados na época onde os sexos ainda não desfrutavam de direitos sociais iguais. De acordo com o censo de 2010, a população enquadrada como Sem Instrução ou com o Fundamental Incompleto no Vale do Rio Pardo corresponde a 56,43\%. No Rio Grande do Sul, a taxa de indivíduos neste nível de escolaridade corresponde a 48,18\% da população, sendo 24,05\% homens e 24,12\%, mulheres; no Brasil, corresponde a 50,24\% da população, sendo 25,53\% homens e 24,72\%, mulheres. Os números encontrados no Vale do Rio Pardo são maiores do que os regionais e nacionais, e isto ocorre em função dos momentos históricos, culturais e sociais, que influenciam a visão que o idoso tem sobre qual a importância que a educação tem nesta fase de sua vida e também de como foi a sua educação ao longo da vida.

A proporção de idosos identificados como Sem Instrução ou com o Fundamental Incompleto do Vale do Rio Pardo corresponde a 13,4\% da população, de acordo com dados de 2010, índice considerado alto se compararmos com a realidade do restante do estado e do país. Os municípios com os maiores índices deste nível educacional são Vale Verde (19,42\%), seguido de Sinimbu (18,54\%), General Câmara (16,18\%), Vale do Sol (15,86\%), Mato Leitão $(15,85 \%)$ e Passo do Sobrado (15,84\%). No Rio Grande do Sul, corresponde a 11,29\% da população, sendo 4,78\% homens e 6,5\%, mulheres; em relação à população do Brasil, a taxa corresponde a 9,49\%, sendo 4,17\% homens e 5,32\%, mulheres (IBGE, 2010). 
Alguns idosos incorporam mitos com relação à sua capacidade de aprender a ler, escrever, sobre assuntos em geral e com isso acabam se sentindo excluídos da sociedade. Sabe-se que o envelhecimento não altera a capacidade de aprendizagem da pessoa e, até quando há presença de alterações que limitam ou condicionam as habilidades sensoriais, não há declínio na função intelectual do idoso (DOMINGOS; MARTINS, 2008).

No censo de 2000, percebeu-se que no Brasil o número de mulheres idosas com o Ensino Fundamental completo - 439.836 (0,51\%) - é maior do que o de homens idosos $365.864(0,43 \%)$. No Rio Grande do Sul, percebe-se também esta realidade, sendo que, há $38.591(0,68 \%)$ mulheres idosas para 29.346 (0,51\%) homens idosos. No Vale do Rio Pardo também se observa esta diferença, tendo sido identificadas $904(0,22 \%)$ mulheres e 718 $(0,18 \%)$ homens. Em Ibarama, Mato Leitão e Vale Verde não há homens com o Ensino Fundamental Completo. Já em Sobradinho e Vale do Sol não há mulheres com este nível educacional concluído. Destaca-se que, no censo de 2000, nos municípios de Herveiras, Passa Sete e Passo do Sobrado não havia homens e mulheres idosas com o Ensino Fundamental Completo.

Em nosso país, o nível de escolaridade da população idosa é baixo. Uma das razões para este fenômeno pode ser o fato de que na primeira metade do século passado, período médio de nascimento de pessoas que hoje são idosas, o acesso à escola era ainda muito restrito. Esse quadro é explicado pelas políticas educacionais da época. Até os anos 1950, a universalização do Ensino Fundamental não era obrigatória, ficando reservada a determinados segmentos da sociedade. Não existia um acesso igualitário entre as classes sociais, nem entre os sexos (DOMINGOS; MARTINS, 2008). As oportunidades educacionais para pessoas idosas continuam sendo postergadas; apesar do aumento da expectativa de vida, nos últimos tempos, encontramos índices muito baixos de escolaridade na população idosa, principalmente no meio rural (VERAS et al., 2003).

De acordo com o censo de 2010, a proporção de indivíduos com Ensino Fundamental completo ou Ensino Médio incompleto do Vale do Rio Pardo corresponde a 17,98\% a população total. No Rio Grande do Sul, corresponde a 18,96\%, sendo 9,41\%, homens e 9,55\%, mulheres; no Brasil, corresponde a 17,40\%, sendo 8,48\% homens e 8,91\%, mulheres.

Já observamos que a população idosa com Ensino Fundamental Completo ou Ensino Médio Incompleto do Vale do Rio Pardo, neste período, corresponde a 1,28\% da população toal. Os municípios com maiores índices deste nível educacional são General Câmara (1,65\%), seguido de Rio Pardo (1,64\%), Candelária (1,58\%), Encruzilhada do Sul (1,54\%), Santa Cruz do Sul 1,53\% e Sobradinho (1,48\%). Da população total do Rio Grande do Sul, os 
idosos com este nível de escolaridade correspondem a $1,7 \%$, sendo $0,73 \%$ homens e $0,98 \%$, mulheres; no Brasil, correspondem a 1,08\%, sendo 0,48\% homens e 0,6\%, mulheres (IBGE, 2010).

Em 2000, em nível nacional e estadual, as mulheres idosas estão em maior número quanto ao Ensino Médio Completo, 462.603 (0,54\%) e 30.778 (0,54\%), respectivamente, enquanto o número de homens idosos é de $372.396(0,44 \%)$ e 25.388 (0,44\%), respectivamente, para este nível de escolaridade. Já nos dados do Vale do Rio Pardo percebese que os homens idosos ainda estão em maior número, mesmo que esta diferença seja pequena - $589(0,14 \%)$ mulheres e $701(0,17 \%)$ homens.

De acordo com o censo de 2010, os indivíduos com Ensino Médio Completo ou Superior Incompleto do Vale do Rio Pardo correspondem a 19,26\% da população total, permanecendo a taxa menor que a estadual e a nacional. A população total do Rio Grande do Sul com este nível de escolaridade corresponde a $23,75 \%$, sendo $11,21 \%$ homens e $12,53 \%$, mulheres; no Brasil, corresponde a 23,45\%, da qual 10,85\% são homens e 12,60\%, mulheres. Nestes dados percebe-se a inversão em relação à escolarização, também um pouco abaixo dos índices estadual e nacional.

Em nosso país, bem como em quase todos os países do mundo, as mulheres sempre tiveram maiores barreiras no acesso à escola. Alguns países conseguiram derrubá-las, mas, em outros, ainda há uma longa batalha pela frente (BELTRÃO; ALVES, 2009). O ensino superior brasileiro vem se expandindo, de maneira geral, com o aumento de matrículas em cursos de graduação nos últimos 20 anos. A faixa etária de mulheres na qual se tem grande quantidade de matrículas tem sido acima dos 24 anos de idade (SCHWARTZMAN, 1999).

A população idosa com Ensino Médio completo ou Superior incompleto do Vale do Rio Pardo corresponde a $0,95 \%$ da população total, sendo $0,44 \%$ homens e $0,49 \%$ mulheres. Os municípios com maiores índices deste nível educacional são General Câmara (1,97\%), seguido de Santa Cruz do Sul (1,47\%), Rio Pardo (1,38\%), Encruzilhada do Sul $(1,14 \%)$, Pantano Grande $(0,84 \%)$ e Venâncio Aires $(0,82 \%)$. A população do Rio Grande do Sul com este nível de escolaridade corresponde a $1,53 \%$ do total, sendo que $0,68 \%$ são homens e $0,85 \%$ são mulheres; e no Brasil corresponde a $1,25 \%$, sendo $0,56 \%$ homens e $0,69 \%$ mulheres (IBGE, 2010).

Como ainda há ausência de uma política pública específica para educação do idoso, percebe-se a necessidade desta, pois isso permitiria que pudessem aprender mais e transformar sua maneira de pensar e agir. O Vale do Rio Pardo aparece em menor número em mais de um nível educacional, se comparado ao Brasil e ao RS, e este fator deve ser visto 
como um desafio para novas políticas públicas que estimulem o acesso e a oportunidade de retornar ou iniciar a educação formal nos diversos municípios.

No censo de 2000, nos níveis educacionais mais baixos, as mulheres se destacaram em maior número, entretanto, no que se refere ao Ensino Superior - Graduação, são os homens que apresentam níveis mais altos. No Brasil, o número de homens idosos com graduação é de 292.796 (0,34\%) e de mulheres 203.373 (0,24\%); no Rio Grande do Sul é de $21.475(0,38 \%)$ e $16.990(0,30 \%)$, respectivamente. Nos municípios do Vale do Rio Pardo também se observa uma diferença, embora menor: $436(0,10 \%)$ homens idosos e $393(0,09 \%)$ mulheres idosas com este nível de escolaridade. Em nível nacional e estadual, o maior número de idosos com Mestrado e Doutorado são homens, sendo 23.547 (0,03\%) no Brasil e 1.349 $(0,03 \%)$ no Rio Grande do Sul. Já no Vale do Rio Pardo não há nenhum homem idoso com este nível educacional e apenas 10 (0,02\%) mulheres. Estas são residentes do município de Santa Cruz do Sul, na zona urbana, onde há presença de uma Universidade.

De acordo com o censo de 2010, a população com Ensino Superior Completo do Vale do Rio Pardo corresponde a 6\%, sendo ainda menor que a nacional e a estadual. A população total do Rio Grande do Sul com este nível de escolaridade corresponde a 8,66\% e a do Brasil corresponde a 8,31. Em termos de população idosa, o mesmo fenômeno se observa, com apenas $0,7 \%$ da população com Ensino Superior Completo no Vale do Rio Pardo. Os municípios com maiores índices deste nível educacional são Encruzilhada do Sul (1,19\%), seguido de Sobradinho (1,1\%), Santa Cruz do Sul (1,09\%), Rio Pardo (0,79\%), Venâncio Aires $(0,72 \%)$ e General Câmara (0,69\%). No Rio Grande do Sul a população com Ensino Superior Completo corresponde a $1,13 \%$ do total de indivíduos, sendo $0,53 \%$ homens e $0,61 \%$ mulheres, e a população do Brasil corresponde a $0,88 \%$, sendo $0,44 \%$ homens e $0,44 \%$ mulheres (IBGE, 2010).

Nos dias atuais, grande parte dos programas educacionais destinados à população idosa segue o antigo modelo francês, o qual tem o centro de suas atividades em educação permanente, de modo que este seja um espaço onde os idosos podem se relacionar e utilizar o seu tempo livre, estudar e participar de cursos regulares ou cursos organizados conforme seu perfil (PACHECO, 2006). Os resultados obtidos indicam que o acesso à educação dos idosos ainda está diminuto, embora haja melhora. No que se refere ao gênero, observa-se que os homens tiveram sempre mais acesso do que as mulheres mesmo após a entrada da mulher na educação formal e no mercado de trabalho. Apesar das mudanças ocorridas nos últimos anos, observa-se que, mesmo com um diploma na mão, algumas mulheres optam por deixar tudo de 
lado após o casamento e se dedicar somente à casa, ao marido e aos filhos, sendo seu companheiro o único provedor de suas necessidades materiais.

Segundo Pacheco, 2006, p. 226:

No Brasil, após um período de experiência e aprendizagem com as atividades de educação para os idosos, tem-se buscado consolidar e ampliar os objetivos desses programas em consonância com as diretrizes maiores da educação nacional, mesmo com todas as dificuldades de um país ainda em crescimento populacional onde a educação não é prioridade para o conjunto da sociedade.

Alguns estudos associam que a ideia de ter uma educação para idosos se alicerça no propósito de busca de um sujeito que está em processo continuado de tomada de consciência e de crescimento pessoal.

\section{CONSIDERAÇÕES FINAIS}

Os dados analisados demonstram que a baixa escolaridade dos idosos está presente em ambos os sexos no que diz respeito aos residentes no Vale do Rio Pardo - RS, onde a maioria não possui instrução ou possui o Ensino Fundamental incompleto, nos censos de 2000 e de 2010. Porém, já se verifica que, no último censo, houve um aumento significativo referente à escolaridade das mulheres idosas, que estão em maior número em todos os níveis, apontando para uma inversão no gênero em relação aos níveis educacionais em nosso país.

Destaca-se, também, um aumento da oferta de programas educacionais para idosos, como exemplo as Universidades Abertas para a Terceira Idade, proliferadas em todo o país desde a década passada. Estas Universidades têm uma proposta diferente para os idosos que antes não tiveram a oportunidade de estudar, pois elas instrumentalizam estes indivíduos com conhecimentos e informações e possibilitam uma maior interação entre gerações e destas com o mundo. Consideramos, ainda, que deva haver mais debates entre os profissionais e gestores públicos sobre a necessidade de ampliar as políticas ligadas à população idosa, de modo a melhorar as condições de vida, o bem-estar e a dignidade, sem deixar de lado as mulheres que estão assumindo papel importante na sociedade, inclusive como provedoras. Entende-se que, a partir da educação, é possível derrubar mitos a respeito do envelhecimento e derrubar preconceitos como o de que os idosos não aprendem, ou são mais lentos para aprender, que gostam de viver isolados, que perderam sua capacidade de concentração e sua atenção, contribuindo para melhoria da qualidade de vida. 


\section{REFERÊNCIAS}

AREOSA, S. V. C.; AREOSA, A. L. Envelhecimento e dependência: desafios a serem enfrentados. Revista Textos \& Contextos, v. 7, n. 1, p. 138-150, 2008.

BIASOLI-ALVES, Z. M. M. Continuidades e Rupturas no Papel da Mulher Brasileira no Século XX. Psicologia: Teoria e Pesquisa, v. 16, n. 3, p. 233-239, 2000.

CARVALHO; J. A. M.; GARCIA, R. A. O envelhecimento da população brasileira: um enfoque demográfico. Cadernos de Saúde Pública, v.19, n. 3, 2003.

BELTRÃO, K. I.; ALVES, J. E. D. A reversão do iato de gênero na educação brasileira no século XX. Cadernos de Pesquisa, v. 39, n. 136, p. 125-156, 2009.

IBGE - Instituto Brasileiro de Geografia e Estatística. Censo Demográfico 2010. Disponível em: 〈http://www.sidra.ibge.gov.br/cd/cd2010ETRD.asp>. Acesso em: 10 de mar. de 2013.

Censo Demográfico 2000. Disponível em:

$\langle$ http://www.sidra.ibge.gov.br/cd/defaultcd2000.asp?o=19\&i=P>. Acesso em: 20 de mar. de 2013.

DALLEPIANE, L. B. Envelhecimento Humano: Campo de saberes e práticas em saúde coletiva. Ijuí: Editora Inijuí, 2009.

DOMINGOS, A. M.; MARTINS, M. T. S. L. Além dos espaços escolares convencionais, mulheres idosas em um grupo de alfabetização e apoio escolar. TEIAS, v. 1, n. 18, p. 60-67, 2008 .

INEP. Instituto Nacional de Estudos e Pesquisas Nacionais Anísio Teixeira. Ministério da Saúde. Perfil dos Dirigentes Municipais da Educação. 2010. Disponível em: http://www.publicacoes.inep.gov.br/arquivos/\%7B5481B939-40CE-4E24-B887-

7F47148D6FF3\%7D_Perfil\%20Dirigentes\%20Municipais.pdf. Acesso em: 20 de ago. de 2013.

LIMA; L. C. V. de; BUENO, C. M. L. B. Envelhecimento e Gênero: a Vulnerabilidade de Idosas no Brasil. Revista Saúde e Pesquisa, v. 2. n. 2, p. 273-280, 2009.

MARQUES, D. T.; PACHANE, G. G. Formação de educadores: uma perspectiva de educação de idosos em programas de EJA. Revista Educação e Pesquisa, v. 36, n. 2, p. 475 490, 2010.

MARTINS, V.: Alfabetização a conquista da liberdade. Brasil Responsável, v. 4, p. 18-23, 2004.

MELO, H. P. Gênero e pobreza no Brasil. In: CEPAL - COMISSÃO ECONÔMICA PARA AMÉRICA LATINA E CARIBE. Relatório final do projeto Governabilidad Democratica de género em América Latina y en el Caribe. Brasilia: CEPAL/SPM, 2005.

OLIVEIRA, R. de C. da S. Políticas públicas, educação e a pesquisa sobre o idoso no Brasil: diferentes abordagens da temática nas teses e dissertações. Trabalho apresentado no IX ANPED SUL, Seminário de pesquisa em educação da Região Sul, 2012. Disponível em: 
http://www.ucs.br/etc/conferencias/index.php/anpedsul/9anpedsul/paper/viewFile/1845/243.

Acesso em: 20 de nov. de 2013.

PACHECO, J. L. As Universidades Abertas à Terceira Idade como espaço de convivência entre gerações. In: SIMSON, O. R. M.; NERI, A. L.; CACHIONI, M. As múltiplas faces da velhice no Brasil. Campinas: Editora Alínea, 2006.

PERRACINI, M. R.; FLÓ, C. M. Funcionalidade e Envelhecimento. Rio de Janeiro: Guanabara, 2011.

SANTOS, I. B. Oficinas de estimulação cognitiva em idosos analfabetos com Transtorno Cognitivo leve. Dissertação (Programa de Pós Graduação Stricto Sensu em Gerontologia) Universidade Católica de Brasília, 2010.

SCORTEGAGNA, P. A.; OLIVEIRA, R. C. S. Educação: integração, inserção e reconhecimento social para o idoso. Revista Kairós Gerontologia, v. 13, n. 1, p. 53-72, 2010.

SILVA, L. R. F. Da velhice à terceira idade: o percurso histórico das identidades atreladas ao processo de envelhecimento. História, Ciências, Saúde, v. 15, n. 1, p. 155-168, 2008.

SALGADO, C. D. S. Mulher Idosa: a feminização da velhice. Revista Estudos interdisciplinares do envelhecimento, v. 4, p. 7-19, 2002.

SCHWARTZMAN, S. O Ensino Superior no Brasil. Brasília: Ministério da Educação, 1999.

VERAS, R.; PEREIRA, R. S.; CURIONI, C. C. Perfil demográfico da população idosa no Brasil e no Rio de Janeiro em 2002. Textos sobre Envelhecimento, v. 6, n. 1, p. 37-46, 2003. 